\title{
Chapter 6 \\ How COVID-19 Has Changed the Digital Trajectory for Professional Advisory Firms
}

\author{
Charlotta Kronblad and Johanna E. Pregmark
}

\begin{abstract}
As COVID-19 affects populations across the globe, the measures to prevent its spread are increasingly affecting our economies. Restrictions on the movement of people and goods and regulations for social distancing and quarantine affect both the consumption and production of goods and services. In this article, we examine the impact of COVID-19 on professional advisory service providers assisting their clients to excel. We find that COVID-19 has rapidly broken down several previous barriers to digital transformation and has caused a rapid increase in the adoption of digital technology among professional advisory firms. We conclude that although there might be a corona bump of rapid digital implementation, a new normal has been established, which changes the operational context and implies that the rate of digital trajectory will be steeper, and the pace will be faster, than has been earlier anticipated. This implies that professional advisors will become better suited to advise on the increasingly complex digital context of their clients.
\end{abstract}

Keywords Professional advisors $\cdot$ PSFs $\cdot$ Digital transformation · Organizational change $\cdot$ COVID-19

\subsection{Introduction: Why This Chapter Is Important}

COVID-19 is currently affecting economies and people worldwide. In addition to the apparent medical consequences, we have experienced a wide range of economic consequences emerging from the measures adopted to prevent the spread of COVID19. These measures, which involve restrictions on the movement of people and goods

\footnotetext{
C. Kronblad $(\varangle)$

Department of Technology Management and Economics, Chalmers University of Technology, Gothenburg, Sweden

e-mail: chakro@chalmers.se

\section{J. E. Pregmark}

Center for Higher Ambition Leadership Europe, Department of Technology Management and Economics, Chalmers University of Technology, Gothenburg, Sweden e-mail: pregmark@chalmers.se
}

J. Lee and S. H. Han (eds.), The Future of Service Post-COVID-19 Pandemic, Volume 1,

The ICT and Evolution of Work,

https://doi.org/10.1007/978-981-33-4126-5_6 
across borders and regulations prescribing social distancing and quarantine, have meant that both production and consumption patterns have shifted.

This chapter discusses what COVID-19 has entailed for professional service industries and moving forward, what development we can expect for firms in these industries. When we examine how different industries have been impacted by COVID-19, we find large variation. While many industries are negatively impacted by COVID-19 (e.g., tourism, restaurants, and retail) and some industries enjoy a positive impact due to rising demand (e.g., online gaming and medical suppliers), the impact on professional service firms (PSFs) is not as clear-cut. Compared to other types of firms, PSFs are unique (von Nordenflycht 2010) as the main value from their services is not created in their domain. Rather, they facilitate the value creation of their clients (Svensson and Grönroos 2008). Therefore, the demand for professional services is highly affected by the impact on the industries of their clients. While booming economies can influence and increase the need for professional services, bankruptcies and economies in distress may also increase the demand for certain professional services.

While the scope of PSFs is rather broad and includes healthcare providers as well as architectural firms and advertisers, we limit this study to the more classic PSFs (von Nordenflycht 2010), where we particularly examine law and management consultancy firms (hereafter called professional advisory firms), as these firms are directly involved in value-creating activities for their client firms. Although these two types of PSFs do not necessarily commence their digital transformation from an identical level, they share many of the same challenges and opportunities that appear during the process of digital transformation. We seek to understand how these PSFs have been affected by, and how they have adapted to, the situation caused by COVID-19. Exploring how these service professionals cope with COVID-19 is not only interesting for their own sake but also carries a larger societal value. As these types of advisors are directly involved in the value creation process for their clients, their responses to COVID-19 also play a part in how well they equip client firms with tools to overcome the crisis. These professional advisors have an impact that transcends their firm boundaries and direct areas of operations into the operational space of their clients.

For these professional advisors, the impact of COVID-19 is multi-faceted. It affects their external context - the world of their clients-which impacts demand in terms of what services are sought and to what extent (e.g., increasing disputes relating to contracts, disputes on liabilities and force majeure, advice on how to solve liquidity problems, and how to apply for and use government aid and recovery packages that have been allocated to fight the economic crisis). COVID-19 also impacts the internal context and affects how advisors work in the context of their firms.

In this chapter, we dive deeper into how professional advisors manage the impact of COVID-19 on their internal work. We explore whether COVID-19 has had an effect on their internal way of work and discuss what this means for the future development of professional advisors and their firms. We argue that imposed quarantine and rules on social distancing mean that these professionals have largely turned toward virtual 
ways of work and undergone a rapid digital transformation, which has a lasting effect on their internal affairs and those of their clients.

The remainder of this chapter is arranged as follows. First, we briefly describe our qualitative study, outlining the empirical data collection method. Second, we set the stage for our discussion by describing the empirical context, enabling an understanding of what is special about professional service providers (von Nordenflycht 2010; Kronblad 2020; Pemer 2020) and their firms (what characterizes them and what aspects have [yet] served as barriers to their emerging digital transformation). Here, we introduce a theoretical framework to discuss our findings by relating to previous research around barriers to change in general (Kotter 2008) and digital change in particular (Davenport and Westerman 2018), as well as the literature covering digital transformation as such (Reis et al. 2018; Kronblad 2020). Moreover, we include theoretical contributions regarding system change (Beer 2009) and societal impact (Kim et al. 2017) to better interpret how digital changes in professional advisors will impact the new normal. Third, we present our findings and show how COVID-19 has affected their internal workstyle. Fourth, we discuss what these current changes mean for the proposed theoretical framework. In effect, we argue that previous barriers to change, such as lack of change capabilities, technological skills, and sense of urgency, as well as cultural barriers (Kotter 2008; Kronblad and Pregmark 2019), have rapidly vanished, creating a new normal for professional advisors and their firms. Finally, we conclude the chapter by stating that COVID-19 has created an instant increase in digital activities among professional advisors and changed their digital transformation trajectory, which has increased both in terms of pace and rate of transformation. This means that professional advisors and their firms should not expect to return to what was considered normal before the COVID-19 outbreak, and the changes that are currently underway will not only remain but also strengthen in the future. Thus, the impact of COVID-19 means that professional advisors and other PSFs are subject to not only temporary corona bumps in their digital trajectory but also accelerated rate of digitalization post COVID-19, in both their own organizations and in society.

\subsection{Method: Collection and Understanding of Evidence from the Field}

We selected a qualitative research approach as it is often considered appropriate when striving to understand why a phenomenon occurs (Denzin and Lincoln 2005) and explore the complexity of an ongoing development (Eisenhardt and Graebner 2007). We are clearly exploring such a situation. Furthermore, in this study we have we have seen the empirical context and theoretical fields as intertwined. Therefore, we have used principles of systematic combining, developed by Dubois and Gadde (2002). These principles stipulate that researchers in social sciences can gain in understanding when allowing themselves to go back and forth between theory and the empirical observations. 
We collected empirical data through semi-structured interviews with 10 senior legal advisors and 10 senior management consultants. To gain a wider understanding of the context, we also interviewed four additional professionals experts (two judges and two professors) in these industries. We conducted nine interviews through video, five at the interviewees' offices, six outside offices in a city park, and four over the telephone. All interviewees resided in Sweden and all interviews were conducted in Swedish in April 2020. Each interview lasted 30-45 min, during which detailed notes were taken, and specific quotes were written down.

The Swedish research context was chosen because of its convenience. Sweden has previously been discussed as a suitable setting for studies of emergent changes in PSFs because of its liberal legislation (Paterson et al. 2003), allowing for different responses to disruption and digitalization. Moreover, to expand the research context and ensure its validity for a broader application (Rothbauer 2008), we participated in six global virtual conferences discussing the impacts of, and responses to, the COVID-19 outbreak within the selected field of management and legal consultancy. We also gathered additional data through press releases and news articles describing how legal firms and management consultancies have started to respond to the situation at hand.

The data was coded into emerging categories. We then analyzed the data by interpreting it in relation to the literature, as suggested by Eisenhardt and Graebner (2007). We also utilized theories around phenomenon-based research (Schwarz and Stensaker 2014; Von Krogh et al. 2012), advocating that a practical phenomenon (here, the effects of the outbreak of COVID-19 on digitalization of professional advisory firms) often needs to be understood through various theoretical lenses. A phenomenon-based approach is also claimed to be suitable when aspiring to develop knowledge that equally benefits both theory and practice (Von Krogh et al. 2012), which is the objective of this chapter.

Figure 6.1 shows how we used the extant literature to comprehend the collected data. We first tried to understand the specifics of the empirical context and details of the responses toward digital transformation among professional advisors and their firms - that is, how and why these firms have resorted to digital models. Here, we recognize the empirical context by the particularities of PSFs (von Nordenflycht 2010; Pemer 2020) and the specific impact of digitalization on these firms (Kronblad 2020). We combine this with general theories around change (Davenport and Westerman 2018; Fredberg and Pregmark 2018; Kotter 2008) and the pace of digital transformation (Kronblad 2020; Reis et al. 2018). To discuss the potential long-term consequences of the new normal, we also worked to understand the findings in relation to the literature around system shifts (Beer 2009) and societal effects (Frey and Osborne 2017; Kim et al. 2017). Thus, we analyzed the data and discussed it in relation to the above-mentioned three levels. 


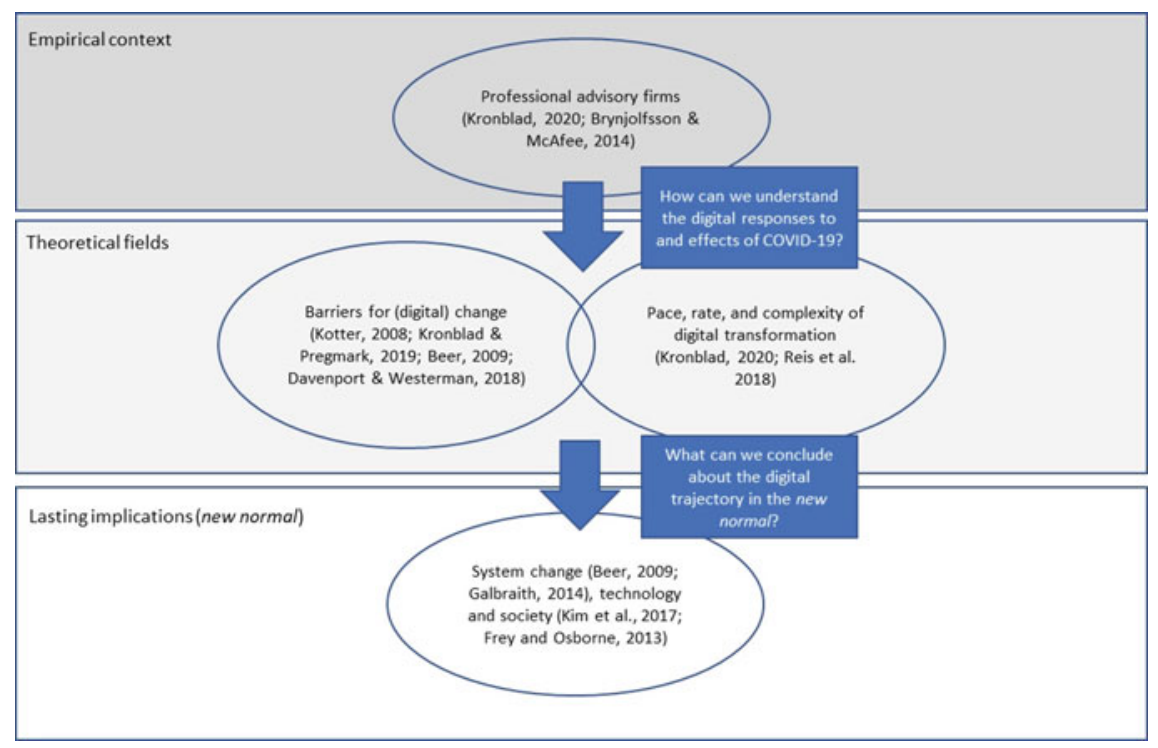

Fig. 6.1 Overview of research fields and literature used to understand the empirical data

\subsection{Theoretical Framework}

To understand the current rapid digital transformation of professional advisory firms and what this transformation means for the future, we need to create a theoretical baseline that we apply to our findings - this section outlines this theoretical framework. First, we dive into the specific empirical context of PSFs, that encompasses the studied professional advisory firms; thereafter, we present general theories on change and the digital transformation (what are the barriers and what motivates change). Finally, we present the literature that suggests the need for system change for lasting effects and the establishment of a new normal.

\subsubsection{Theories Describing the Empirical Context of Professional Advisory Firms}

PSFs are special types of firms whose primary goal is not their success but to strive for the excellence of their clients (Svensson and Grönroos 2008). PSFs succeed when they provide their clients with services that enable them to mitigate risk and create and capture value. In the past, PSFs have been based on human knowledge intensity, where value has mainly been created by human capital at work (von Nordenflycht 2010). However, the recent literature points to the increasing relevance of technological and structural capital within PSFs, wherein artificial intelligence is expected 
to gain positions (Brynjolfsson and McAfee 2014; Huang and Rust 2018; Kronblad 2020). This has catalyzed change in PSFs, both internally and with regard to their clients. As structural and technological capital participates in value creationreplacing and complementing human capital-artificial intelligence is increasingly replacing human intelligence for particular tasks. This suggests that PSFs have been on a path toward increasing digitalization during the past decades. However, while other industries have undergone rapid transformations (Fredberg and Pregmark 2016; Shibata et al. 2019), most PSFs have followed at a slower pace (Kronblad and Pregmark 2019; Pemer 2020).

We specifically targeted professional advisors in management and law that are often described as typical forms of PSFs (von Nordenflycht 2010). Several scholars have investigated the particularities of these types of firms (Maister 2003; Løwendahl 2009; von Nordenflycht 2010; Kronblad 2020; Pemer 2020). One key feature that these researchers highlight is that these firms are often organized in the form of professional partnerships. This structure is formed because of the foundation for value creation being embedded in the human capital of the employed professionals (Løwendahl 2009). Partnership structures have also entailed particular incentive structures such as bonus schemes. In this context, the professionals invest their time and are awarded in the form of promotion. This is typically done in up or out promotions (von Nordenflycht 2010), which are particularly common within the hierarchical structures of elite organizations. These types of practices and organizations mean that both financial benefits and status are incorporated into the current way of work (Kronblad and Pregmark 2019), which has reduced the speed of change. While the classic PSFs share many of the same challenges and opportunities in digitalization, it is notable that legal and management advisors do not necessarily begin from the same position toward their aim of digital transformation-it has been shown that established law firms have previously been particularly late and slow in digital transformation (Kronblad and Pregmark 2019), whereas the pace in management consultancies is higher.

\subsubsection{Theoretical Fields: Change and Digital Transformation}

Organizational change and transformation are broad topics where researchers from many different fields offer valuable contributions. In a fast-paced world, the capability for change and adaptation is more important than ever (Pasmore 2015; Reeves and Deimler 2011). However, research shows that most change efforts fail (Beer et al. 1990; Jacquemont et al. 2015). Here, we focus on some of the barriers and facilitators for change that have been outlined by previous research.

Barriers and resistance to change in organizations is a well-investigated topic in the extant literature (Beer 2007; Conner 1992; Coch and French 1948; Oreg 2003; Rock and Cox 2012). Lawrence (1969) argues that people usually do not resist a specific change but the social relational change that accompanies major changes. This is consistent with the findings of Beer (2007), claiming that it is the fear of losses to relationships, rewards, and identity, which are the root causes of resistance 
to change. The fear of losing status, such as formal and/or informal roles, is also frequently referred to as a barrier for succeeding with change (Beer 2007; TraderLeigh 2002). Other streams of research stress that resistance can be overcome by demonstrating a compelling vision of a future state along with a clear process and an organization-wide sense of urgency/dissatisfaction with the current state (Kotter 2008; Beckhard and Harris 1987; Hayes 2018; Cady Jacobs et al. 2014). Conner (1992) argues for the need for messages of pain being dispersed in the organization, contributing to a strong motivation to leave behind the old way of working.

There are certain barriers to change that are particularly relevant for knowledgeintensive industries, where value creation has been based on the human capital employed in service production (von Nordenflycht 2010) and technological skills have not been needed or asked for (Susskind 2010). Professional advisors have relied on their intellectual capacity and not been exposed to technology being embedded in their work in the manner that professionals in other industries have. Professional advisors also share an institutionalized professional culture (Kronblad and Pregmark 2019), which builds on hierarchies, promoting homogeneity where risk is largely avoided (particularly legal advisors, who are trained to avoid legal risk). This risk avoidance has empowered cultures that prevent them from encouraging innovation. Moreover, successful business models in these industries have, over time, become institutionalized. This has created a path dependency (or rather, a curse of a successful past), which means that these firms have not sensed any urgency to change. Even if they would have sensed a need to change, the high level of institutionalization in these industries means that they lack change capabilities (these firms have simply not needed such capabilities in the past).

Many authors have discussed the specifics of digital transformation (Kronblad 2020; Kronblad and Pregmark 2019, Davenport and Westerman 2018; Reis et al. 2018). These authors discuss how digitalization affects internal processes, external value proposition, and business models, arguing that the transformation impact is greater as digitalization targets a holistic perspective of the organization. Thus, digital transformation requires an interplay of a multitude of components, such as systems, capabilities, and offerings (Davenport and Westerman 2018). In many industries, digital transformation has been seen as a matter of death or survival. As examples, there have been academic contributions regarding this presented for the newspaper industry (Fredberg 2003; Fredberg and Pregmark 2016; Wang 2002), photo/film industry (Shibata et al. 2019), manufacturing (Björkdahl 2020), and retail (Srinivasan et al. 2002). However, in some parts of professional services, this type of urgency has been missing (Kronblad 2020). 


\subsubsection{Lasting Implications of Technological Shifts in Organizational Systems and Society}

Previous research has advocated that the entire organizational system needs to be addressed to succeed with a change in the long-term (Beer 2009; Galbraith 2014; Nadler and Tushman 1980; Pregmark 2019). However, this is easier said than done. Beer, interviewed in Fredberg and Pregmark (2017), states that researchers and practitioners have not yet managed to fully understand and execute system change. Researchers studying system change argue that an organization should be viewed as interrelated parts, where the whole is greater than the sum of its parts. Thus, organizational behavior cannot be understood by studying only the parts. Following that argument, if an organization strives to establish a new behavior, for the desired change to be sustainable, the whole system needs to adapt to support this new behavior within the organization.

Although different models have been proposed for describing organizational systems (see for instance Galbraith 2014 or Nadler and Tushman 1980), they generally include components relating to direction, structure, culture, and capabilities. Here, we will use a system framework to discuss the extent to which the COVID-19 outbreak has influenced the system in the professional advisors to predict the lasting effects of the new normal.

An examination of previous technological shifts reveals that they have had substantial and lasting implications for organizational systems and society (Abernathy and Utterback 1978; Rogers 1995). It has been recognized that invention and diffusion of new technologies often accompany progress, but with potential downsides, because power dynamics, work content, and job opportunities can shift. Digitalization, which provides opportunities for exponential growth and new values to be created, is no exception. However, as noted by Frey and Osborne (2017) and Kim et al. (2017), digitalization can also raise unemployment levels as humans are replaced by algorithms, machines, and robots. As PSFs are changing in terms of digitalization, it could have multiple effects for society, which could be interesting when exploring the new normal.

\subsection{Findings and Data Analysis: What We Learned from the Field}

We collected data on how professional advisors manage the impact of COVID-19 in terms of its effects on their work. The coded statements from the interviewees and notes from the conferences were organized according to temporality as we explored what the data revealed about what had happened, what barriers that had been eliminated in the process, and what this could mean for the future. Hence, first we examined the impact of COVID-19, so far, on digital practices and activities 
among professional advisors and their firms (von Nordenflycht 2010; Susskind and Susskind 2015). Second, we coded the data in terms of what these new practices entailed in relation to barriers to change, analyzing, for instance, the challenges in the established professional cultures, where resistance to change has been built upon established relationships, reward structures, and identities (Beer 2007). Third, we studied what the data suggested about the potential impact of these changes in a future business landscape. We did so in light of the different components that need to be aligned for a large-scale system change (Beer 2009).

Thus, when coding and analyzing the data, we explored what the current changes, inflicted by the current pandemic, meant for the practices of professional advisors and whether these changes were profound enough (and influential enough to the entirety of the system) not to be reverted post COVID-19. In this section, data is reported and analyzed, whereas the findings and analysis is put in relation to the theoretical framework in the discussion section.

\subsubsection{What Digital Effects Did We See for Professional Advisors?}

All interviewees told us that they had experienced quick adoption of digital tools ever since COVID-19 started. "It feels like we skipped forward five years [of digital transformation]" one interviewee told, and another claimed that "We have gotten used to the digital tools very fast." A third interviewee claimed that "Corona is making the digital transformation more relevant than ever" and another one stated that "Really, the digital transformation is irreversible."

We received similar impressions from the conferences that we attended. "What we experience now is disruptive innovation," was claimed in a conversation focusing on law and legal businesses. Another comment was that "We are moving toward a new normal," and that "The question is not if anymore, it is when," describing how COVID-19 had moved the needle toward digitalization. Moreover, many participants discussed that the pace of digital transformation is unprecedented. As put by one participant, "It is fair to say that no one thought we would get here, just 1.5 months ago."

The main change from previous practice was described as the increasing opportunities to work from home and increased activity for online collaborations and meetings, as well as the experience that tools and technology have radically improved during this short time. One interviewee added that the increased use of digital technology had an impact on whom to collaborate with, stating "It is new times, and they call for new collaborations." There is also a new need to collaborate with different digital actors and those with access to and competence in different digital technologies. One interviewee, however, added that "Technology is not the solution in itself, it is only part of it." explaining that a shift in mindset and an effective process of implementation of the technology is needed. 
When asked about the practical details of the novelty to their work, the discussion among the legal advisors quickly turned to virtual courts and new implications in courts. This was seen as a good and explicit example of digital transformation. One interviewee expressed, "We see courts now taking an active part in the digital society." Both completely virtual and hybrid courtrooms (allowing some participation online) were discussed, with interviewees stating that "We just got new possibilities to hear witnesses via their cell phones, and last week we had a witness calling in sick in the morning, and instead of canceling the entire hearing we could go ahead with the trial. It is really efficient and works very well, so I cannot see that we would go back and not allow that in the future," "The transformation that we have seen in the courts in these corona-times is really an opportunity to increase access to justice;" and "We have started to use virtual courtrooms for some cases, and I don't think that we will go back."

Some interviewees also discussed a new collaborative landscape relying more on trust than lengthy negotiations, and a new and improved contract language-often described as simpler and more pertinent. As put by one interviewee, "To simplify is really the trickiest, what seems to be simple may really be very complex." One interviewee claimed that digitalization, by its nature, puts higher demands on language, "You need to be very precise when it comes to digital tools, and pay attention to detail."

\subsubsection{Have Change Barriers Been Broken?}

It is imperative to understand the changes in the work processes and models of professional advisors and their firms, in light of the empirical context, and examine whether COVID-19 imposed changes (reported above) will have a lasting effect on these firms. To explore this, we analyzed the findings in order to understand the barriers that could have been potentially eliminated during COVID-19. The data suggested that several barriers, such as lack of technological skills, change capabilities and sense of urgency, as well as institutionalized traditional professional culture (building on risk avoidance), had been affected. Quotes related to these themes are reported below. While some of the quotes respond to the breakdown of several barriers, we have placed these in the column where we perceive that these statements have the largest effect (Table 6.1). 
Table 6.1 Findings: quotes depicting the breakdown of previous barriers

\begin{tabular}{|c|c|c|}
\hline $\begin{array}{l}\text { Barrier number } 1-\text { Lack of } \\
\text { technological skills and change } \\
\text { capabilities }\end{array}$ & $\begin{array}{l}\text { Barrier number } \\
\text { 2-Traditional culture } \\
\text { building on risk avoidance } \\
\text { (Lack of trust) }\end{array}$ & $\begin{array}{l}\text { Barrier number 3-Lack of } \\
\text { sense of urgency }\end{array}$ \\
\hline $\begin{array}{l}\text { "Many of the partners and } \\
\text { senior consultants - me } \\
\text { included - did not really want } \\
\text { to learn and use new tools. } \\
\text { Perhaps we were a bit afraid of } \\
\text { feeling stupid. Perhaps we } \\
\text { were lazy. Anyway, it turned } \\
\text { out it was possible to teach the } \\
\text { old dogs how to sit after all." }\end{array}$ & $\begin{array}{l}\text { "We have been fine with } \\
\text { digitalization of our internal } \\
\text { work but always said that the } \\
\text { customer interface demands } \\
\text { personal interaction in real } \\
\text { life. We argued that a new } \\
\text { digital way of working would } \\
\text { not provide the right sense of } \\
\text { confidence. Er... we are now } \\
\text { proven wrong." }\end{array}$ & $\begin{array}{l}\text { "Why would we stop our } \\
\text { extensive traveling, why would } \\
\text { we try digital models - the one } \\
\text { we used seemed to be } \\
\text { working." }\end{array}$ \\
\hline $\begin{array}{l}\text { "Lack of adoption has really } \\
\text { been a barrier. Legal tech tools } \\
\text { have really been regarded too } \\
\text { complex, not concrete enough, } \\
\text { and not really helping the } \\
\text { users, but now it looks like the } \\
\text { technology is much better } \\
\text { adapted to user needs." }\end{array}$ & $\begin{array}{l}\text { "This is a really complex } \\
\text { transformation because } \\
\text { lawyers and judges are all } \\
\text { very conservative, and they } \\
\text { have not wanted to change in } \\
\text { the past, but now there is no } \\
\text { choice." }\end{array}$ & $\begin{array}{l}\text { "Well, that is clear: we have } \\
\text { digitalized faster because we } \\
\text { had to." }\end{array}$ \\
\hline $\begin{array}{l}\text { "I now know that I can conduct } \\
\text { a very efficient workshop } \\
\text { through digital tools that I had } \\
\text { not even heard of a few months } \\
\text { ago." } \\
\text { "I still believe I need to meet } \\
\text { with my customers. But digital } \\
\text { ways of working will forever be } \\
\text { a part of my toolbox." }\end{array}$ & $\begin{array}{l}\text { "I think we have been } \\
\text { hesitant to really pursue new } \\
\text { technology, especially in the } \\
\text { customer value proposition. } \\
\text { At least I was afraid that I } \\
\text { would lose my edge, lose } \\
\text { what I do well." }\end{array}$ & $\begin{array}{l}\text { "Actually, I think that it has } \\
\text { been a problem that everyone } \\
\text { in the senior partner group is } \\
\text { older than } 40 . \text { We have had an } \\
\text { old-fashioned way of looking } \\
\text { at things. Now we were forced } \\
\text { to at least dip our toes in the } \\
\text { future." }\end{array}$ \\
\hline
\end{tabular}

\subsubsection{What Does This Mean for the Future?}

The third step in our data analysis was to explore what the breakdown of barriers implies for the continued digital trajectory of professional advisory firms.

From our findings, it is clear that COVID-19 has impacted the current digital environment of these firms, effecting changes that are highly likely to continue in the future (causing a system change in the long-term). While the interviewees bring up many positive effects in terms of value creation and sustainability, rapid digitalization could also create new risks for which professional advisors need to reconsider how they work. A rapid digital transformation also causes unintended side effects that range from smaller issues-where professional advisors express that they need to improve the experience and quality of the digital work and value propositions- to the initiation of larger questions on what the rapid digital transformation means for 
Table 6.2 Findings: quotes depicting the implications of the new normal

\begin{tabular}{|c|c|c|}
\hline $\begin{array}{l}\text { New practical issues to } \\
\text { manage in the new normal }\end{array}$ & $\begin{array}{l}\text { To prepare professionals for } \\
\text { the new normal }\end{array}$ & $\begin{array}{l}\text { Future implications of the new } \\
\text { normal }\end{array}$ \\
\hline $\begin{array}{l}\text { "With new practices come new } \\
\text { challenges, for instance, we } \\
\text { previously did not have a } \\
\text { problem with background } \\
\text { noise, or people not focusing } \\
\text { during the trial, but when } \\
\text { people attend from home there } \\
\text { are suddenly children running } \\
\text { around in the background or } \\
\text { someone is vacuuming, so it is } \\
\text { hard to create the same air of } \\
\text { respect for the legal process. } \\
\text { But I guess that this is } \\
\text { something that we will work on } \\
\text { that will develop over time." }\end{array}$ & $\begin{array}{l}\text { "We find that this new } \\
\text { situation demands new skills } \\
\text { and competencies. Really, we } \\
\text { need creative persons that } \\
\text { want to develop the system } \\
\text { and the professional role, but } \\
\text { we have experienced that that } \\
\text { is very hard to find. Law } \\
\text { school does not produce that } \\
\text { kind of lawyers." }\end{array}$ & $\begin{array}{l}\text { "The future depends on us, and } \\
\text { how we handle this situation } \\
\text { will determine how the future } \\
\text { will look." }\end{array}$ \\
\hline \multirow[t]{2}{*}{$\begin{array}{l}\text { "While there is a lot of good in } \\
\text { this fast transformation, we } \\
\text { need to be careful and think } \\
\text { also about what in human } \\
\text { interaction that is lost." }\end{array}$} & $\begin{array}{l}\text { "You do not really use the } \\
\text { stuff you learn in legal } \\
\text { education." }\end{array}$ & $\begin{array}{l}\text { "When we digitalize it is } \\
\text { important that we do it with } \\
\text { care. Public trust depends on } \\
\text { us doing this right." }\end{array}$ \\
\hline & $\begin{array}{l}\text { "This will change a very } \\
\text { conservative industry, which } \\
\text { means that also education } \\
\text { needs to be reconsidered." }\end{array}$ & $\begin{array}{l}\text { "We are making the future and } \\
\text { we need more imagination and } \\
\text { we need to create new utopias } \\
\text { that should guide our quick } \\
\text { digital adoption." }\end{array}$ \\
\hline
\end{tabular}

the future labor markets, what type of professionals we need to progress, and how we should educate them.

Examples of how the interviewees in this study reflected upon the future are reported in Table 6.2. Potentially, this means we need to shift the education and training of professionals to reflect the new normal and rethink business models and service delivery to become more aligned with the new normal.

\subsection{Discussion: Rapid Digital Transformation of Professional Advisory Firms}

Below, we discuss how this rapid shift to digital ways of working can be understood and why we believe that these effects are likely to last. We also hypothesize how the shifted digital trajectory of professional advisory firms can affect society in the new normal (building onto system change), wherein professional advisory firms will be better aligned to advising in other simultaneously transforming and complex contexts. 


\subsubsection{How Can We Understand Digital Transformation During the COVID-19 Outbreak?}

Previous research has suggested that the level and speed of digital transformation can be understood through its impact on internal, external, and/or holistic firm dimensions (Kronblad 2020; Reis et al. 2018). Here, we observe that COVID-19, understood as an external shock, has caused a rapid increase in the digital transformation of professional advisory firms. For instance, there has been an increased use of digital tools and technology with new ways of work, including a transformation of physical workplaces to virtual workspaces enabling remote work and remote access. One good example of this is the increased use of virtual courts, although they are not ordinary workplaces for all professional advisors. This shows that a traditional institution such as the court can work virtually, which poses the question that why other services cannot follow this path. Thus, we observe that these extraordinary times have entailed extraordinary changes, which society has increasingly accepted and trusted. One interviewee claimed that she had skipped five years of digital transformation, while another stated that what seemed impossible just a few months ago was suddenly possible. It seems that we have entered a phase of a new normal-a new much more digital normal.

To understand the new normal and anticipate what will happen after COVID-19, we need to understand the current extraordinary situation in light of the ordinary situation. We need to explore if the current extraordinary practices will last-in particular, if the extraordinary circumstances have made such changes to the ordinary context, which have eliminated certain barriers, causing the system to change for lasting effects.

Our findings show that under extraordinary circumstances (here in the shape of COVID-19), extraordinary measures (that have previously not been accepted) can suddenly be both prescribed and trusted. Our findings indicate that current practices have effectively broken down previous barriers to change (comprising cultural components and the lack of technological competencies and a sense of urgency) and built the base for a new normal from where the digital transformation will not only commence but also increase in terms of both rate of change and speed. We argue that the rapid shift to digital models (imposed by COVID-19) has affected internal processes, which have ultimately also affected their external constituents as well as those of the firms in a holistic sense (Kronblad 2020; Reis et al. 2018). The organizations of these professional advisors, reluctant to change just months ago, have undergone a dramatic shift, which suggests that several of the previously strong barriers to change have simultaneously been broken down.

Our data analysis specifically points toward three previously identified major barriers to change that have been eliminated by COVID-19. These are a lack of technological skills and change capabilities (Kronblad and Pregmark 2019), risk avoidance and lack of trust (Kronblad 2020) and lack of a sense of urgency (Kotter 2008). While new technological skills and change capabilities are needed for the continued digital transformation, it is also necessary that a new professional culture 


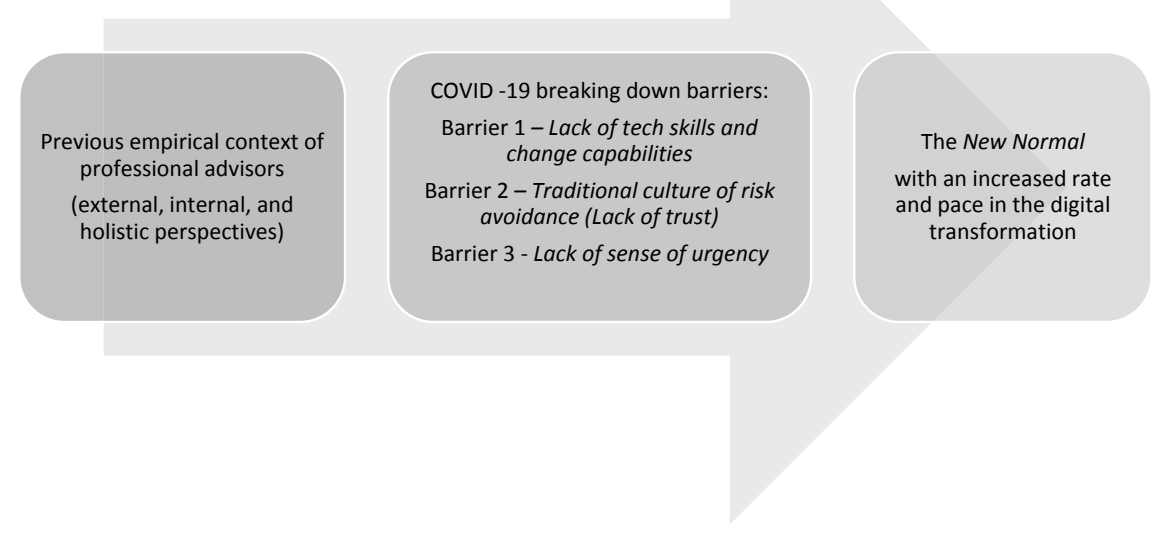

Fig. 6.2 The components of coronavirus-induced change

is developed that better aligns with the new normal. This culture needs to be more accommodating to a larger professional variation and collaboration with external parties and innovation and risk-taking than the previously established culture of professional advisors (which has been more focused on risk avoidance than innovation). Moreover, the presence of urgency is clear in a situation with restrictions and social distancing. The need for a sense of urgency is almost univocally stressed as an important prerequisite for realizing a successful change (Beckhard and Harris 1987; Conner 1992; Hayes 2018; Kotter 2008). However, this urgency has previously been demonstrated to be, at least partly, lacking among PSFs (Pemer 2020; Kronblad 2020).

Figure 6.2 shows how the COVID-19 outbreak - as an external shock — is dramatically changing the digital context and effectively eliminating barriers to change. This, in turn, creates the basis for lasting effects in both professional advisors and society and engenders system change that form the new normal.

\subsubsection{A Shifted Digital Trajectory Departing from the New Normal}

Many authors have addressed that organizational transformation needs to be systemic (Beer 2009; Beer et al. 1990; Galbraith 2014) to last. Recently, this notion has also been brought in research around digital transformation, where research has discussed the need to view digital transformation as a part of changing the system rather than focusing on the technology shift as such (Davenport and Westerman 
2018; Kronblad and Pregmark 2019). We argue that COVID-19 has forced PSFs in general, and professional advisory firms in particular, to a digital system shift, where internal processes, external propositions, and business models have been affected. Davenport and Westerman (2018) describe how digital transformation needs to be addressed through various intertwined measures-requiring investments in strategy, skills, infrastructure and information technology systems, people, machines, and business processes. To address such system activities and processes have previously proven particularly hard for legal advisors (Kronblad 2020). We argue that this has been possible in a very short period due to COVID-19 effectively breaking down at least three obstacles to digital transformation (lack of technological competence, lack of sense of urgency, and cultural components). These barriers have been broken down simultaneously and have further enabled system change and expedited the process.

We argue that COVID-19, by effectively breaking down some of the strongest barriers to change among professional advisors, has enabled a rapid shift toward technological implementation and digital business models. Moreover, we argue that this shift addresses internal, external, and business model changes. Thus, in just a few months, the digital transformation seems to have reached all levels, creating a new normal from a holistic perspective.

Hence, what COVID-19 has done is to accelerate system change (Beer 2009; Galbraith 2014) wherein many intertwined processes are involved. During a short period, digitalization has found its way into strategy, structure, processes, capabilities, and culture, unlike previously when it was viewed more as a project targeting specific (often internal) work processes. This is particularly true for professional advisory firms, as their internal transformation also has an external impact through more relevant advisory services in an overhanging external context. Management consultants describe how digitalization came closer to their value proposition and customer interface and legal advisors describe how they rapidly embraced more processual and internal digital practices. However, although management consultants and legal advisors did not start from the same level of digitalization (legal firms are often described to be slow to adapt, see Kronblad 2020), interviewees from both camps described how COVID-19 forced changes affecting the whole organizational system.

This is also in line with how Davenport and Westerman (2018) argue around a success model for digital transformation, including the alignment of multiple elements. Researchers within the field of organizational change have previously argued that a system change is difficult to accomplish (Beer 2009), however necessary, for lasting effects. The data collected clearly show that COVID-19 has provoked the investigated organizations to react as individual parts of a larger system where the individual changes interrelate and further affect each another, leading us to believe that these organizations are well on the way toward a systemic shift in their digital trajectory. Moreover, new organizational capabilities (structural as well as individual) have been built into organizations during a very short period. Therefore, we anticipate that the new normal is only the beginning. 


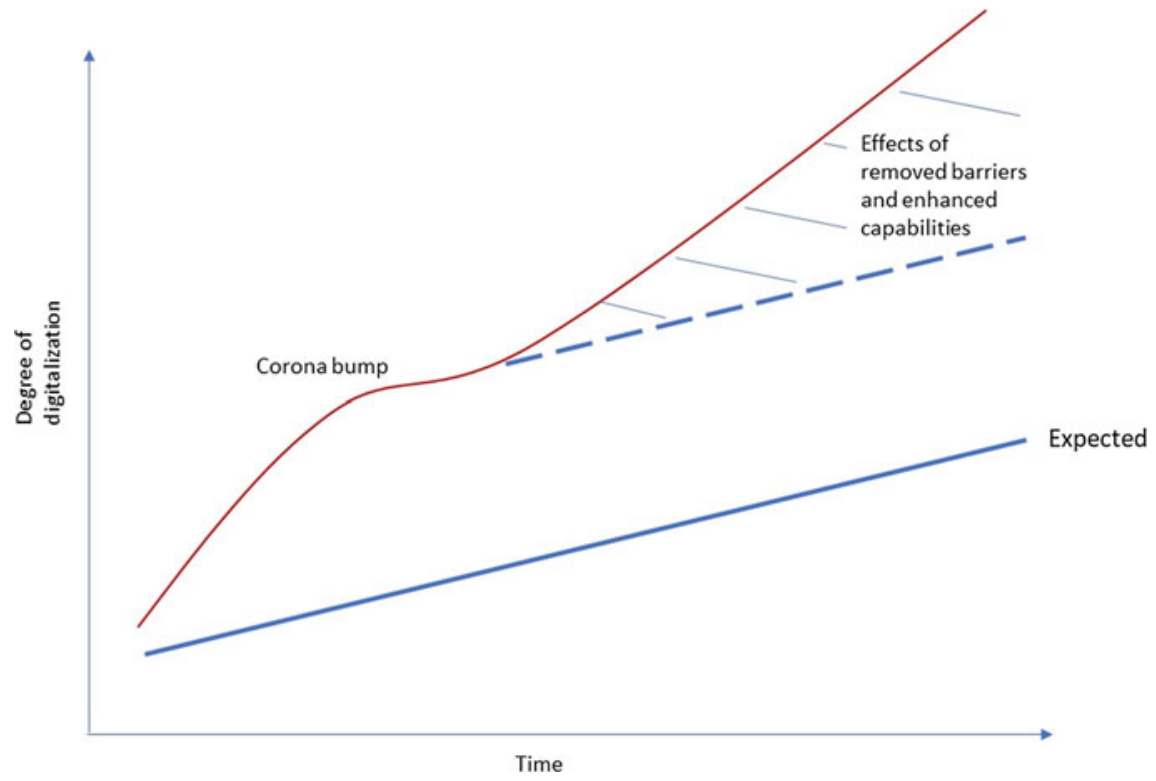

Fig. 6.3 The digital transformation trajectory of professional advisory firms

We propose that the shift to digital work processes, offers, and business models is much more than a "bump" in the digital trajectory for professional advisory firms. As important barriers have been broken down and organizations seem to have changed as systems (Galbraith 2014; Beer 2009; Pregmark 2019) in a very short period, we believe that in the future, we will witness an increased pace and rate of digital transformation. We argue that new capabilities have been built, which, in turn, will continue this acceleration. This is depicted in Fig. 6.3.

We-along with many of our interviewees - see great possibilities in the longterm potential effects of a shifted digital trajectory for professional advisory firms. It is easy to observe the potential in new value creation models, more sustainable ways of working, and more widespread access to professional advisors. This is further accelerated by the roles that professional advisors have in relation to their clients (Svensson and Grönroos 2008). A more efficient digital transformation of the advisors also has the potential to spill over to the contexts of their clients, while improving their advisory services in terms of better, faster, and more relevant content. Thus, the digital transformation of professional advisors will ultimately have further effects on all the external markets and contexts of their clients.

However, we would also like to stress the need for a cross-disciplinary discussion on the unintended consequences of this shifted and accelerated digital trajectory for professional advisory firms. As previous research has pointed out (Abernathy and Utterback 1978), technological advances often have several different impacts on society, which can redraw the landscape of the labor market, the competence required, and power distribution. Recent research on digital shifts shows a similar 
pattern. Kim et al. (2017) and other researchers (Susskind and Susskind 2015; Huang and Rust 2018) have highlighted that human work is increasingly being replaced in this shift toward digital ways of working. Thus, as the speed of digitalization increases substantially - as we predict - this might lead us to the need to consider new curves to flatten in the new normal, for instance, curves representing increasing unemployment.

\subsection{Conclusion}

In this chapter, we have shown that COVID-19 has had several effects on the work of professional advisory firms, and potentially other PSFs, and that these changes have altered the empirical context of these firms to the extent that the changes will likely last, leading to systemic change. COVID-19 has effectively meant that firms have gained technological skills and change capabilities that will remain past the outbreak, which will increase the rate of digital transformation. This has also altered the previous homogenous and traditional professional cultures of professional advisors, which has opened up for increased heterogeneity and collaboration with others, thereby ensuring increased responsiveness to other external shocks in the future. Lastly, COVID-19 has created an instant sense of urgency that has increased the speed of digital transformation: "the question is not if anymore, it is when". This implies that even if we experience a corona bump - reflecting an instant and short term increase in digitalization among professional advisory firms with remote work and virtual meetings that will revert once restrictions on social distancing are liftedthe experiences that the firms have gained means that there is no old normal for them to return to. Instead, we witness the development of a new normal, where the trajectory of the digital transformation of professional advisory firms increase in both rate and pace. With increased technological skills and change capabilities, and a culture that accepts risk-taking, these firms are better suited to adapt to future needs. These changes among professional advisory firms are particularly important in their capacity to provide other firms (in various industries) with advice on how to conduct their businesses to create value. This implies that the digital trajectory of professional advisory firms also has a large influence on the larger digital trajectory of markets and society.

\section{Authors' Insight}

We argue that the rapid turn toward digital ways of working, that we are currently experiencing, will have lasting effects on professional advisors, as well as on society as a whole. We believe that professional advisors can be seen as catalysts in this transformation-where their value proposition and the way that they conduct their services affects how a wide range of other industries perform. This is because the 
main purpose for professional service firms is not their own success, but rather the success of their clients. Furthermore, we believe that the accelerated digital transformation of professional advisors will matter greatly by empowering the digital transformation of society at large. This is important, because it might even have effects on some of the great challenges of our time. For instance, the increasing digitalization of legal advisors could open up for larger accessibility to legal advice adding to the democratization of law. This is particularly important for such legal advice that are directed toward citizens that have previously not afforded, or been able to access, legal services. The increased application of digital technologies ultimately making legal services cheaper, faster and more accessible while potentially also being more consistent, un-biased and reaching a higher quality. On top of democratizing the legal landscape, digitalization could also entail an increased use of sustainable business models and ways of working across professional advisors and their firms in general. This could even out the competitive playing field, which would arguably bring potential benefits to external firms and individuals alike. Perhaps, when physical distance is erased as an obstacle, this will also support new ways of leading and managing organizations. The digital transformation of professional advisors could further push an agenda (stressed by several researchers) for discussing how to ensure that great leaps in technological advances are used for the benefit of society.

However, it is not all upsides, but we also see risks. If professional advisors can be seen as catalysts in the digital transformation, we should also consider what it means for society if this progress is too fast and accelerates out of control. In this chapter, we call for a discussion around these potentially negative impacts on industries and societies. We foresee that technology will increasingly be replacing humans in the workforce (at least for some work tasks). This will potentially lower prices, increase quality and create better access to legal and business advice, however it will also potentially create new curves to flatten and pose new challenges to solve. For instance: will rapid technological dispersion create unemployment? For whom? Who will gain and who will lose? Is this rapid turn to digital business models and ways of working creating an even greater divide between haves and have-nots? These are also some of the greatest questions of our time, and they remind us that we need to look at digitalization in a holistic sense and understand how it is implemented into the system and what wider impacts this transformation will entail.

Once we have landed in the new normal, some things will probably go back to the way they were; with people partly returning to their old ways of working and organizing. But this chapter shows us that previous barriers for adopting digital ways of working, that professional advisors have previously run into, have forever been torn down. We believe this is a good thing, and that this could potentially help solving some crucial challenges in society-but this rapid transformation could also come with unintended consequences, and those we should all engage in mitigating. 


\section{References}

Abernathy, W. J., \& Utterback, J. M. (1978). Patterns of innovation in industry. Technology Review, 80(7), 40-47.

Beckhard, R., \& Harris, R. T. (1987). Organizational transitions: Managing complex change. Reading, MA: Addison-Wesley Publishing Company.

Beer, M. (2007). Leading change, Harvard Business School background note 488-037 (Revised January 2007).

Beer, M. (2009). High commitment, high performance: How to build a resilient organization for sustained advantage. San Francisco, CA: Jossey-Bass.

Beer, M., Eisenstat, R. A., \& Spector, B. (1990). The critical path to corporate renewal. Boston, MA: Harvard Business School Press.

Björkdahl, J. (2020). Strategies for digitalization in manufacturing firms. California Management Review, 62(4), 0008125620920349.

Brynjolfsson, E., \& McAfee, A. (2014). The second machine age: Work, progress, and prosperity in a time of brilliant technologies. New york, NY: W. W. Norton.

Cady, S. H., Jacobs, R., Koller, R., \& Spalding, J. (2014). The change formula: Myth, legend, or lore? OD Practitioner, 46(3), 32-39.

Coch, L., \& French, J. R. P. (1948). Overcoming resistance to change. Human Relations, 1(4), $512-532$.

Conner, D. (1992). Managing at the speed of change. New York: Random House.

Davenport, T. H., \& Westerman, G. (2018, March 9). Why so many high-profile digital transformations fail. Harvard Business Review. https://hbr.org/2018/03/why-so-many-high-profile-digitaltransformations-fail. Accessed 12 Feb 2020.

Denzin, N. K., \& Lincoln, Y. S. (Eds.). (2005). The Sage handbook of qualitative research. Thousand Oaks, CA: Sage.

Dubois, A., \& Gadde, L.-E. (2002). Systematic combining: An abductive approach to case research. Journal of Business Research, 55(7), 553-560.

Eisenhardt, K. M., \& Graebner, M. E. (2007). Theory building from cases: Opportunities and challenges. Academy of Management Journal, 50(1), 25-32.

Fredberg, T. (2003). Interface strategies: Internet and the business of large Swedish daily newspapers. Göteborg: Department of Project Management, Chalmers University of Technology, Institute for Management of Innovation and Technology.

Fredberg, T., \& Pregmark, J. E. (2016). Transformation in a tightly nested system: Employing fast cycles of change. Research on Organization Change and Development, 24, 185-219.

Fredberg, T., \& Pregmark, J. E. (2017). Michael Beer: It's not the seed, it's the soil. In D. B. Szabla, W. A. Pasmore, M. A. Barnes, \& A. A. Gipson (Eds.), The Palgrave handbook of organizational change thinkers. Cham: Palgrave MacMillan.

Fredberg, T., \& Pregmark, J. E. (2018). Organization renewal through corporate entrepreneurship: When the seed changes the soil. In A. B. R. Shani \& D. A. Noumair (Eds.), Research on organization change and development (Vol. 26). Bingley, UK: Emerald Publishing Limited.

Frey, C. B., \& Osborne, M. A. (2017). The future of employment: How susceptible are jobs to computerisation? Technological Forecasting and Social Change, 114, 254-280.

Galbraith, J. R. (2014). Designing organizations: Strategy, structure, and process at the business unit and enterprise levels. San Fransisco: Jossey-Bass.

Hayes, J. (2018). The theory and practice of change management. London: Palgrave Macmillan.

Huang, M.-H., \& Rust, R. T. (2018). Artificial intelligence in service. Journal of Service Research, 21(2), 155-172.

Jacquemont, D., Maor, D., \& Reich, A. (2015, April). How to beat the transformation odds. McKinsey survey. http://www.mckinsey.com/business-functions/organization/our-insights/howto-beat-the-transformation-odds. Accessed 7 Jan 2017.

Kim, Y. J., Kim, K., \& Lee, S. (2017). The rise of technological unemployment and its implications on the future macroeconomic landscape. Futures, 87, 1-9.

Kotter, J. P. (2008). A sense of urgency. Boston, MA: Harvard Business Press. 
Kronblad, C. (2020). How digitalization changes our understanding of professional service firms. Academy of Management Discoveries, published online. https://journals.aom.org/doi/10.5465/ amd.2019.0027.

Kronblad, C., \& Pregmark, J. E. (2019). Beyond digital inventions-Diffusion of technology and organizational capabilities to change. In M. Corrales, M. Fenwick, \& H. Haapio (Eds.), Legal tech, smart contracts and blockchain (pp. 123-146). Singapore: Springer.

Lawrence, P. R. (1969, January). How to deal with resistance to change. Harvard Business Review. https://hbr.org/1969/01/how-to-deal-with-resistance-to-change. Accessed 2 Feb 2020.

Løwendahl, B. R. (2009). Strategic management of professional service firms. Denmark: Copenhagen Business School Press.

Maister, D. H. (2003). Managing the professional service firm. New York: Free press.

Nadler, D. A., \& Tushman, M. L. (1980). A model for diagnosing organizational behavior. Organizational Dynamics, 9(2), 35-51.

Oreg, S. (2003). Resistance to change: Developing an individual differences measure. Journal of Applied Psychology, 88(4), 680-693.

Pasmore, W. A. (2015). Leading continuous change: Navigating churn in the real world. Oakland, CA: Berrett-Koehler.

Paterson, I., Fink, M., \& Ogus, A. (2003) Economic impact of regulation in the field of liberal professions in different member states. Study for the European Commission.

Pemer, F. (2020). Enacting professional service work in times of digitalization and potential disruption. Journal of Service Research, 1094670520916801. Retrieved online.

Pregmark, J. E. (2019). Mastering change through innovative initiatives: Contextual ambidexterity as a process. Gothenburg: Chalmers University of Technology.

Reeves, M., \& Deimler, M. (2011, July-August). Adaptability: The new competitive advantage. Harvard Business Review. https://hbr.org/2011/07/adaptability-the-new-competitive-advantage. Accessed 10 Dec 2019.

Reis, J., Amorim, M., Melão, N., \& Matos, P. (2018). Digital transformation: A literature review and guidelines for future research. Cham: Springer.

Rock, D., \& Cox, C. (2012). SCARF® in 2012: Updating the social neuroscience of collaborating with others. NeuroLeaership Journal, 4, 1-16.

Rogers, E. M. (1995). Diffusion of innovations. New York: The Free Press.

Rothbauer, P. (2008). Triangulation. In L. Given (Eds.), The Sage encyclopedia of qualitative research methods (pp. 892-894). London: Sage.

Schwarz, G., \& Stensaker, I. (2014). Time to take off the theoretical straightjacket and (re)introduce phenomenon-driven research. The Journal of Applied Behavioral Science, 50(4), 478-501.

Shibata, T., Baba, Y., Kodama, M., \& Suzuki, J. (2019). Managing ambidextrous organizations for corporate transformation: A case study of Fujifilm. $R \& D$ Management, 49(4), 455-469.

Srinivasan, S. S., Anderson, R., \& Ponnavalu, K. (2002). Customer loyalty in e-commerce: An exploration of its antecedents and consequences. Journal of Retailing, 78, 41-50.

Susskind, R. (2010). The end of lawyers. New York: Oxford University Press.

Susskind, R. E., \& Susskind, D. (2015). The future of the professions: How technology will transform the work of human experts. USA: Oxford University Press.

Svensson, G., \& Grönroos, C. 2008. Service logic revisited: Who creates value? And who co-creates? European Business Review, 20(4), 298-314.

Trader-Leigh, K. E. (2002). Case study: Identifying resistance in managing change. Journal of Organizational Change Management, 15, 138-155.

Wang, T. T.-Y. (2002, May 9-11). The competitive advantage of online newspapers from strategic positioning and alliances. Paper presented at the 5th World Media Economics Conference, Turku School of Economics and Business, Turku, Finland.

Von Krogh, G., Rossi-Lamastra, C., \& Haefliger, S. (2012). Phenomenon-based research in management and organisation science: When is it rigorous and does it matter? Long Range Planning, 45(4), 277-298. 
von Nordenflycht, A. (2010). What is a professional service firm? Toward a theory and taxonomy of knowledge-intensive firms. Academy of Management Review, 35(1), 155-174.
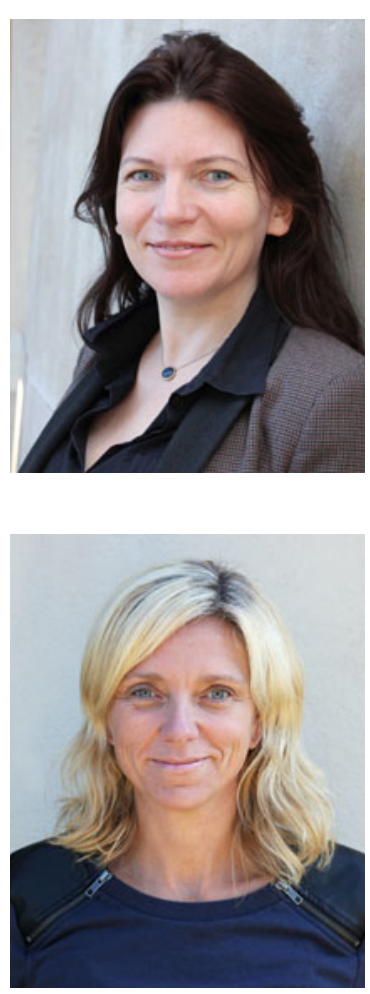

Charlotta Kronblad practiced law for a decade before switching to an academic career at Chalmers University of Technology, where she is currently a Ph.D. candidate. Her first-hand experience of the digital transformation of the legal industry is what awoke her interest to study this phenomenon.

Her research targets the intersections of business and law, and professional and organizational change in times of digital transformation. Her work has been published in Academy of Management Discoveries, Creativity and Innovation Management and in various book chapters.

Johanna E. Pregmark has a Ph.D. from Chalmers University of Technology. Her work has been published in for instance Research on Organization Change and Development, Management Decision and in various book chapters. In parallel to her research, she works as a consultant at TruePoint.

Before re-entering academia, she worked as a management consultant for 15 years, and was partner and at a consultancy firm. She was also part of forming an international alliance of consultancy firms, with transformation as focus. Also, she has experience from various leadership positions. Apart from working with collaborative research in transforming industries, she is part of the core team that drives Center for Higher Ambition Leadership Europe and a Corporate Entrepreneurship initiative at Chalmers School of Entrepreneurship.

Open Access This chapter is licensed under the terms of the Creative Commons AttributionNonCommercial-NoDerivatives 4.0 International License (http://creativecommons.org/licenses/bync-nd/4.0/), which permits any noncommercial use, sharing, distribution and reproduction in any medium or format, as long as you give appropriate credit to the original author(s) and the source, provide a link to the Creative Commons licence and indicate if you modified the licensed material. You do not have permission under this licence to share adapted material derived from this chapter or parts of it.

The images or other third party material in this chapter are included in the chapter's Creative Commons licence, unless indicated otherwise in a credit line to the material. If material is not included in the chapter's Creative Commons licence and your intended use is not permitted by statutory regulation or exceeds the permitted use, you will need to obtain permission directly from the copyright holder.

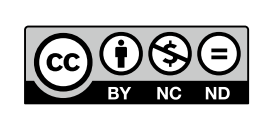

